\title{
Study of Mortality and Causes of Death in the Service of Stomatology, Maxillofacial and Plastic Surgery of the Face at Cocody Teaching Hospital (RCI)
}

\author{
Konan Marc Koffi ${ }^{*}$, Bakary Ouattara1, Abou Dramane Sangaré2, \\ Harefeteguena Christophe Bissa1, Mouan Béatrice Harding-Kaba1, \\ De Misères Opokou Alexandre Ory33, Rokiatou Koné2, Bi Epiphane Kouai1 \\ ${ }^{1}$ Department of Stomatology, Maxillo-Facial and Plastic Surgery of the Face CHU Cocody, Abidjan, Côte d'Ivoire \\ ${ }^{2}$ Department of Public Health UFR-OS, UFHB, Abidjan, Côte d'Ivoire \\ ${ }^{3}$ Department of Stomatology, Maxillo-Facial and Plastic Surgery of the Face CHU Bouaké, Abidjan, Côte d'Ivoire \\ Email: *marckoffi@ymail.com
}

How to cite this paper: Koffi, K.M., Ouattara, B., Sangaré, A.D., Bissa, H.C., Harding-Kaba, M.B., Ory, D.M.O.A., Koné, R. and Kouai, B.E. (2018) Study of Mortality and Causes of Death in the Service of Stomatology, Maxillofacial and Plastic Surgery of the Face at Cocody Teaching Hospital (RCI). Open Journal of Stomatology, 8, 338-344.

https://doi.org/10.4236/ojst.2018.812032

Received: March 16, 2018

Accepted: December 10, 2018

Published: December 13, 2018

Copyright (c) 2018 by authors and Scientific Research Publishing Inc. This work is licensed under the Creative Commons Attribution International License (CC BY 4.0).

http://creativecommons.org/licenses/by/4.0/ (c) (i) Open Access

\begin{abstract}
Introduction: The study of mortality is an indicator that allows a control and a review of the therapeutic measures in the hospital environment. The purpose of this work was to determine the epidemiological profile of the patients who died and analyse the circumstances of the death in a hospital service. Material and Methods: It is a retrospective descriptive study conducted in the service of Stomatology, maxillofacial and plastic surgery of the face over a period of 10 years (from January 1999 to December 2008). Seventy-two cases have been taken into account. Results: The crude death rate was $4.29 \%$. Higher level of male has been noted with a sex ratio of 1.77 . The most affected age groups were the $3^{\text {rd }}$ and $2^{\text {nd }}$ decades, respectively with $20.8 \%$ and $19.4 \%$ with an average age of 39 years. Cellulitis of the face and their complications were responsible for deaths in $58.33 \%$ of cases. The majority of deaths occurred between 6 p.m. and 6 a.m. (65.28\%). These deaths were preventable in $5.6 \%$ of cases. Conclusion: Facing the lack of description of the ultimate circumstances of death in the medical records, the conclusion of this study has been the establishment of a regular medical audit in the service, which would track mortality in order to reduce its rate.
\end{abstract}

\section{Keywords}

Mortality, Causes of Death, Facial Cellulitis 


\section{Introduction}

The study of mortality in a community allows defining the lines of death prevention and readjusting health policy [1]. In a hospital service, such a study allows a control and a review of the therapeutic measures; these are likely to degradation in their implementation over the years, which requires a periodic criticism [2] [3]. If in developed countries this periodic review is systematic in different hospital services, in our tropics, it is practically not the case [4] [5] [6]. Although deaths are numerous, no study makes it possible to focus on the factors and main causes of mortality. This would suggest improvements in the management of personnel and equipment in order to provide care of quality [7] [8].

The Service of Stomatology, maxillofacial and plastic surgery of the face alike the other services of this reference hospital have no unit of death audit. That's why it appeared appropriate to initiate this work which has for objectives:

1) the determination of the epidemiological profile of the patients who died in our service;

2) and the analysis of the death circumstances.

\section{Material and Method}

It is a retrospective descriptive study which took place in the Department of Stomatology, maxillofacial and plastic surgery of the face from January 1999 to December 2008, which is 10 years.

Were included in this study all patients who died during their hospital stay with a medical record to date. However the patients who died before admission and those whose medical record was missing or incomplete were excluded. At the end of the vote count there were 114 deaths and only 72 fulfills our inclusion criteria have been selected for the study.

The information was collected from registers (admissions, hospitalization, and death) and the patient's medical record.

The studied parameters were:

- Mortality indicators [9]: the number of death (number of deaths per year), the crude death rate (number of deaths during a given period reported to the number), the specific rate of mortality (mortality rate calculated according to different variable, ex: age, sex, ...), and the proportional mortality (share that is a cause or a group of causes in general mortality).

- Analysis of the death concerned; the time of occurrence, the length of stay in the service, the immediate cause of death (clinical picture at the time of death), the period of occurrence within one month and the concept of avoidability (fatal outcome which should not have happened if it had wisely been applied the appropriate health technology to the nature of the disease and the level of care).

Data were analyzed from the software epi info 2000 in its 6.2.4 version.

\section{Results Indicators of Death}

Over 1675 inpatients, 114 deaths were recorded, but only 72 cases have been the 
subject of our study. The crude mortality rate is then $4.29 \%$. The highest rates were observed in 2008 (15 cases; 6.91\%) and lowest in 2001 ( 1 case; $0.34 \%$ ) (Figure 1).

The specific rate of mortality by sex is $63.9 \%$ for men and $36.1 \%$ for women, which a sex ratio of 1.77 .

Age groups who have recorded high rates were: 31-40 years old (20.8\%) and 21-30 years (19.4\%). The average age was 39 years and the standard deviation 18.5. This rate was low among adults over the age of 70 years (4.2\%) (Figure 2).

More than half of the patients who died (51.4\%) were without profession, followed by the liberal professions (30.6\%).

Cellulitis have been responsible for deaths in $58.33 \%$ cases followed by malignant

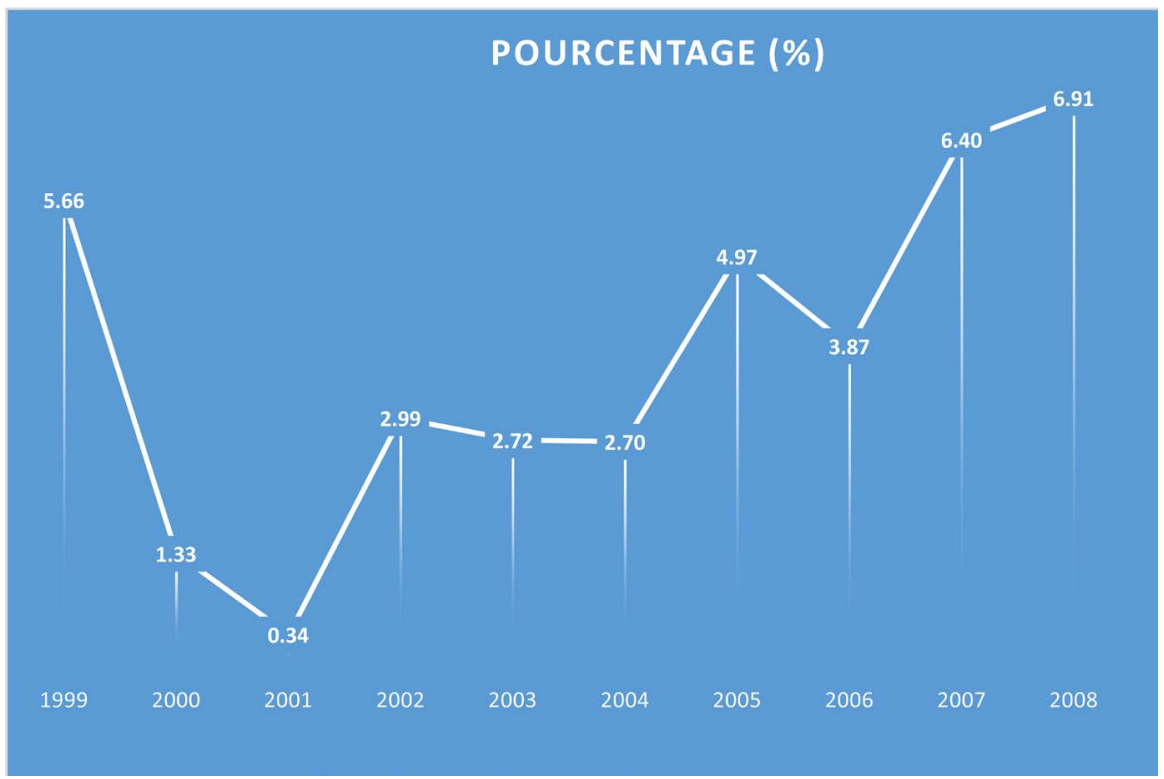

Figure 1. Breakdown by gross mortality rate per year.

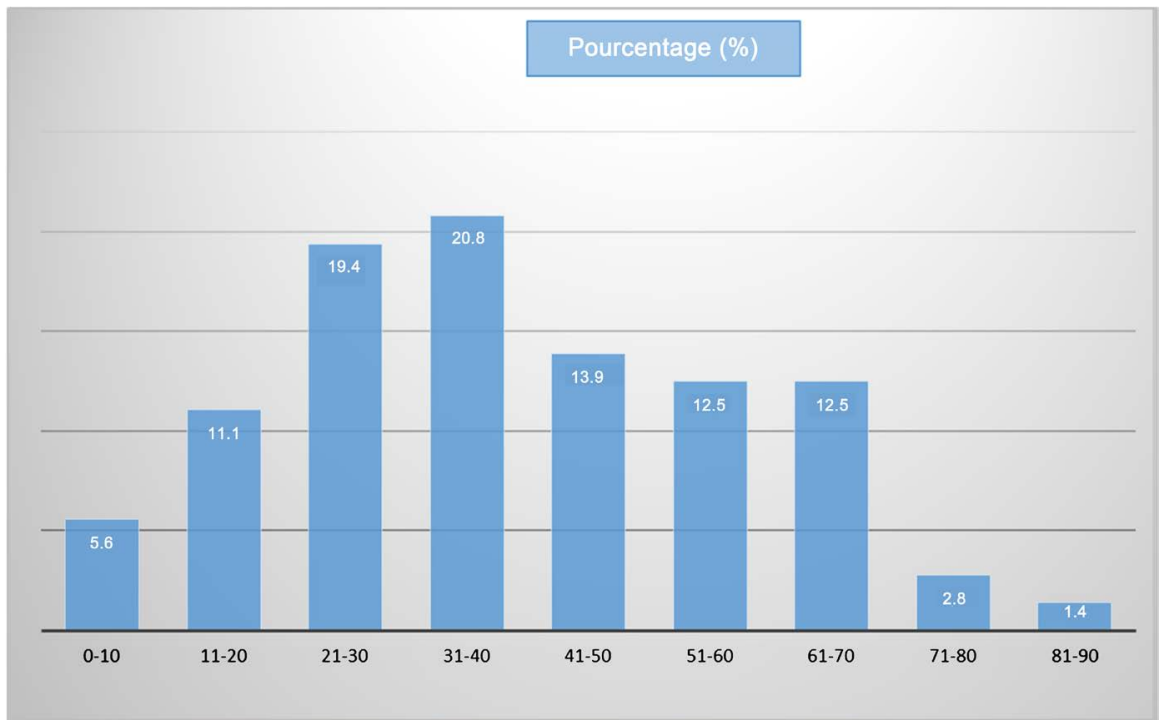

Figure 2. Distribution according to the specific mortality rate by age groups. 
tumours, Burkitt Lymphoma included (20.83\%) (Table 1).

\section{Analysis of the Deaths}

The deaths occurred most often within 48 hours after admission in the service (37.50\%) (Table 2).

About $65.3 \%$ of deaths occurred in the evening and at night, between 6 p.m and 6 a.m.

The circumstances of death were as follows: septic shock (43.05\%) and decompensation of severe anemia (16.66\%) (Table 3).

Table 1. Distribution according to positional mortality.

\begin{tabular}{ccc}
\hline & Size & Percentage \\
\hline Cellulitis & 42 & 58.3 \\
Malignant tumor (including burkitts lynphom) & 15 & 20.83 \\
Norm & 3 & 04.16 \\
Trauma & 2 & 02.77 \\
Osteitis & 2 & 02.77 \\
Lingual oedema & 1 & 01.38 \\
Stomatitis infield of HIV & 3 & 04.16 \\
Polylymphadenopathy & 2 & 02.77 \\
Complicated sinusitis & 2 & 02.77 \\
Total & 72 & 100 \\
\hline
\end{tabular}

Table 2. Distribution of patient who died according to the length of stay.

\begin{tabular}{ccc}
\hline & Size & Percentage \\
\hline $0-48$ Hours & 27 & 37.50 \\
$3-7$ Days & 16 & 22.22 \\
$8-14$ Days & 6 & 08.33 \\
$15-21$ Days & 5 & 06.94 \\
31 Days and More & 4 & 05.55 \\
Total & 72 & 100 \\
\hline
\end{tabular}

Table 3. Distribution of patient who died according to clinical picture at the time of death.

\begin{tabular}{ccc}
\hline & Size & Percentage \\
\hline Septic shock & 31 & 43.05 \\
Decompensated anemia & 12 & 16.66 \\
Respiratory destress & 8 & 11.11 \\
Undernutrition + deshydratation & 5 & 06.94 \\
terminal evolution of malignant tumor & 10 & 13.88 \\
Hypovdemic shock & 4 & 05.55 \\
Not accurate & 2 & 02.77 \\
Total & 72 & 100.0
\end{tabular}


These deaths were inevitable in $83.3 \%$ of the cases, avoidable in $5.6 \%$ of cases and in $11.1 \%$ of cases we could not reach a conclusion.

\section{Discussion}

The hospital mortality during the study period was $4.29 \%$ with peaks in the years 1999 (5.66\%), 2007 (6.4\%) and 2008 (6.91\%). This rate seems high compared to that found by Ftouhi et al. $1.56 \%$ in internal medicine service in Tunis and Dony et al. $1.1 \%$ in surgery service [1] [10]. The study showed a gradual growth of the curve of mortality from 2001 in our service. It is an unsatisfactory trend unlike most hospital services practicing heavy surgery [2] [3]. This high mortality rate could be explained by several factors: the impoverishment of the population in General causing late consultations, the deficit of means of diagnosis and treatment, the lack of maintenance of the existing equipment and the absence of an unit of audit of deaths.

The most affected age groups were those between 31 and 40 years (20.8\%) and between 21 and 30 years (19.4\%) with an average age of 39 years. It is about young and active people. Elsewhere in Africa, Takongmo [7] and Rakotondrabe [6] found respectively 43 and 33 years in Yaounde and Madagascar, while Proye in Lille, France [1] found an average age of 63 years.

The men were most affected with a sex ratio of 1.77 . This result was in line with the excess male mortality found in almost all studies. The majority of the patients who died were without profession (51.4\%), it was in general about poor people with difficulties of support. Cellulitis were the leading causes of death (58.33\%) followed by the malignancies including lymphoma Burkitt (20.83\%). Bakary et al. [11] in a previous study in the same Department had found the cellulitis as being the first cause of hospitalization. These results were almost identical to those of the WHO that classified the causes of mortality as follows in the developing countries by decreasing order: infectious and parasitic diseases, the respiratory system diseases, cancers [12].

Deaths were more frequent between 6 p.m. and 6 a.m. $(65.28 \%)$. This period corresponds to the time of activity of the guard team. It was a small team with a doctor, a nurse and an aid who was responsible for inpatients as well as those admitted in an emergency. Sometimes this team is inexperienced and the workload is disproportionate to the size of the team. For Takongmo [7], who found superposable results, this would allow to accuse a deficiency in the quality of care at the period of guards.

In $37.50 \%$ of cases death occurred within 48 hours after admission. This could be explained by the fact that our patients usually arrived in arrays of complications. The traditional treatment of the traditional healers is also an aggravating factor because patients for reasons of insufficient financial mean begin with this kind of treatment.

Septic shock has been the immediate cause of death in $43 \%$ of cases followed by decompensated anemia in $16.66 \%$ cases. These deaths were preventable in 4 
cases (5.6\%) and 8 cases (11.1\%) the conclusion was impossible. These different situations denote the inadequacy of our intensive care in terms of material and human resources to deal with severe complications of hemodynamic and septic shock [13].

This study shows some limits; In fact, it is about a retrospective study in which we were confronted to some difficulties. In particular, the bad position of dossiers. So, it would be imperious to establish an audit protocol of death in order to describe them well.

\section{Conclusion}

The assessment of mortality remains a permanent concern in day-to-day politics of medicine. This study although limited to one single service allows drawing the attention of the medical team on its shortcomings. There is a need to establish a medical audit system in hospitals whose mission will be to improve quality care.

\section{Conflicts of Interest}

The authors declare no conflicts of interest regarding the publication of this paper.

\section{References}

[1] Ftouhi, B., Taktak, S., Kamoun, M., Ben Brahim, S. and Ben Khalifat, F. (1998) Etude de la mortalité et des causes de décès dans un service interne. Tun Med, 76, 977-984.

[2] Proye, C., Camp, D., Triboulet, J.P., et al. (1988) Mortalité d'un service de chirurgie générale de CHU. Etude de l'année 1985: 1409 opérés, 45 décès post-opératoies. Journal De Chirurgie, 25, 255-259.

[3] Proye, C., Martinot, J.C., Triboulet, J.P., et al. (1991) Mortalité d'un service de chirurgie générale de CHU. Etude sur l’année 1990: 1492 opérés 27 décès post-opératoires. Journal De Chirurgie, 128, 453-458.

[4] Pequignot, F., Jougla, E., Le Tallec, A. and Bovet, M. (2000) Données épidémiologiques sur les causes de décès en France. Rev Prév, 38, 25-33.

[5] Tabassum, N., Rob, R., Cilla, M.R. and Syd, M.M.R. (2007) Audit of Deaths Less than a Week after Admission through an Emergency Department: How Accurate Was the ED Diagnosis and Were Any Deaths Preventable? Emergency Medicine Journal, 24, 691-695. https://doi.org/10.1136/emj.2006.044867

[6] Rakotondrabe, J.B., Rantomalala, H.Y.H. and Randriarimanga, H.B.R. (2008) Les causes de décès d'après une étude thanatologique au CHU-HJRA. Medecine d'Afrique noire, 55, 98-100.

[7] Takongmo, S., Angwafo, F., Binam, F., Afane Ela, A., Fonkoua, A., Gaggini, J., Le Saint, B., Lantum, D. and Malonga, E. (1993) Mortalité hospitalière enmilieu chirurgical: nécessité de l'audit médical. Medecine d'Afrique noire, 40, 72933.

[8] Koueta, F., Yougbare, O.O.S., Dao, L., Dao, F., Ye, D. and Kam, K.L. (2011) Audit desdécès maternels selon le modèle des trois retards, en milieu hospitalier pédiatrique de Ouagadougou. Sante, 21, 209-214.

[9] Michel, E. and Iougla, E. (2000) Principaux indicateurs utilisés pour l'analyse descriptive des causes médicales de décès. Bulletin du Cancer, 87, 655-659. 
[10] Dony, P., Pirson, M. and Boogaerts, J.G. (2017) In- and Out-Hospital Mortality Rate in Surgery Patients. Acta chirurgica Belgica, 118, 1-6.

[11] Bakary, O. (1996) Cellulites maxillo-faciales graves et VIH. Thèse Med, Université de Cocody, Abidjan, 1740.

[12] OMS (2006) Classification Internationale des Maladies et des problèmes annexes (CIM). 10ème révision, OMS, Génève.

[13] Ouedraogo, N., Niakara, A., Simpore, A., Barro, S., Ouedraogo, H. and Sanou, J. (2002) Soins intensifs en Afrique: Expérience des deux premières années d'activité du service de réanimation du centre hospitalier national de Ouagadougou (Burkina-Faso). Santé: Mont rouge, 12, 375-381. 